\title{
La faïence de Nevers (1585-1900)
}

t. 1. Histoires et techniques, 240 p., 140 ill.

t. 2. L'âge d'or du XVII ${ }^{\mathrm{e}}$ siècle, 400 p., 700 ill.)

Dijon, éd. Faton, 2009.

\section{Jean Rosen}

\section{(2) OpenEdition} Journals

\section{Édition électronique}

URL : https://journals.openedition.org/cem/11659

DOI : 10.4000/cem.11659

ISSN : 1954-3093

\section{Éditeur}

Centre d'études médiévales Saint-Germain d'Auxerre

\section{Édition imprimée}

Pagination : 373

ISSN : $1623-5770$

\section{Référence électronique}

Jean Rosen, «La faïence de Nevers (1585-1900) », Bulletin du centre d'études médiévales d'Auxerre / BUCEMA [En ligne], 14 | 2010, mis en ligne le 19 octobre 2010, consulté le 22 septembre 2022. URL http://journals.openedition.org/cem/11659; DOI : https://doi.org/10.4000/cem.11659

Ce document a été généré automatiquement le 22 septembre 2022.

\section{(c) (i) (2) (2)}

Creative Commons - Attribution - Pas d'Utilisation Commerciale - Partage dans les Mêmes Conditions 4.0 International - CC BY-NC-SA 4.0

https://creativecommons.org/licenses/by-nc-sa/4.0/ 


\section{La faïence de Nevers (1585-1900)}

t. 1. Histoires et techniques, 240 p., 140 ill.

t. 2. L'âge d'or du XVII ${ }^{\mathrm{e}}$ siècle, 400 p., 700 ill.)

Dijon, éd. Faton, 2009.

Jean Rosen

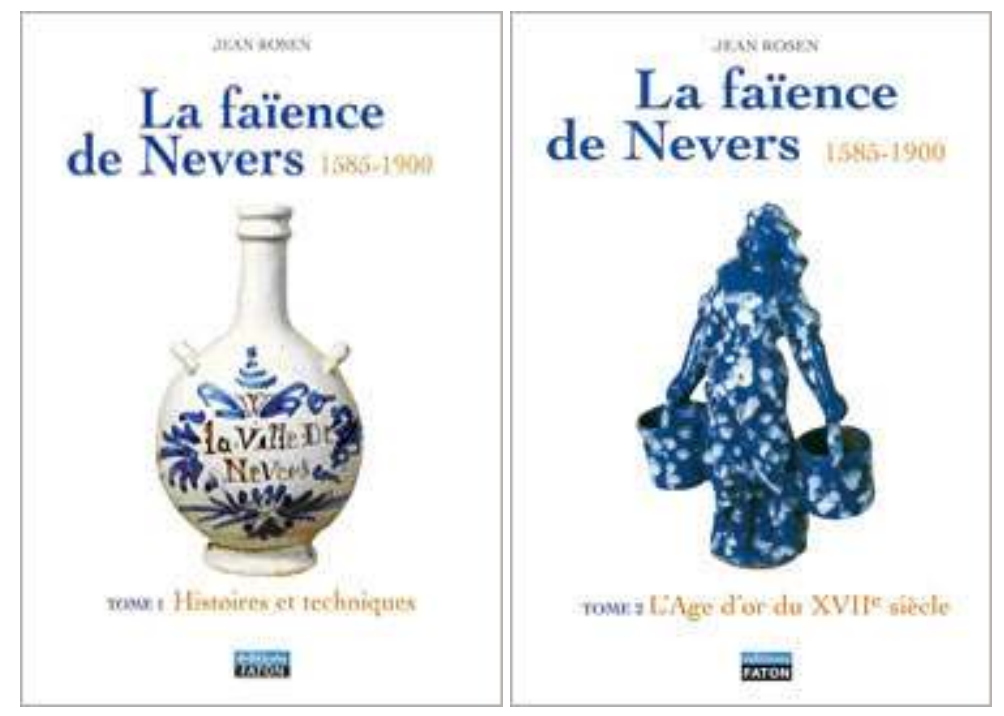

1 Depuis 1585, et sans solution de continuité jusqu'à nos jours, Nevers, aussi bien par son importance historique que par le nombre de ses manufactures - douze en 1755, plus de trente ateliers en tout -, a joué un rôle de tout premier plan dans la propagation et l'évolution de la faïence française, $\mathrm{du} \mathrm{XVI}^{\mathrm{e}}$ au Xx${ }^{\mathrm{e}}$ siècle, et peut être considéré comme le centre idéal pour une recherche sur le long terme.

2 Si la faïence de Nevers a déjà été abordée de multiples façons dans divers colloques et expositions, elle n'a toutefois jamais été traitée avec la vue d'ensemble nécessaire à la compréhension d'un sujet aussi vaste et aussi complexe. Le principal travail d'envergure reste celui de Louis du Broc de Segange paru en 1863, avec de rares illustrations sous forme de gravures en noir et blanc totalement obsolètes. Pour l'essentiel, les nombreuses publications sur le sujet sont extrêmement partielles, et 
ne relèvent la plupart du temps que des seules options du type "arts décoratifs», illustrées d'objets prestigieux sélectionnés au hasard des possibilités et souvent présentés hors contexte.

3 Ce travail, dans son ensemble, constitue l'étude la plus large possible de Nevers en tant que centre faïencier, de la fin $\mathrm{du} \mathrm{XVI}^{\mathrm{e}}$ à la fin du xIX siècle. Il a été élaboré à partir des abondantes archives conservées, des fouilles archéologiques conduites de 1985 à 1989, d'analyses de laboratoire et d'une iconographie très riche, fruit d'une vingtaine d'années de recherches et de collecte dans les collections publiques et privées. L'investigation historique n'y sert pas de simple préambule à la présentation des productions, comme c'est trop souvent le cas. D'autre part, l'iconographie raisonnée présente l'ensemble des productions, attribuées sur des bases scientifiques à partir d'objets de référence souvent datés et des résultats des investigations archéologiques et archéométriques, et non plus sélectionnées à partir de critères esthétiques plus ou moins discutables. In fine, ce projet ambitieux se présentera sous la forme de quatre livres de 300 à 400 pages, très largement illustrés en couleurs, présentés dans deux coffrets et consacrés successivement aux études documentaires générales et au XVII ${ }^{\mathrm{e}}$ siècle (2009), puis aux XVIII ${ }^{\mathrm{e}}$ et XIXe siècles (2011).

\section{Organisation de l'étude}

4 Le premier tome, intitulé Histoires et techniques, est consacré à des études documentaires générales qui couvrent l'ensemble de la période, de 1585 à 1900. Elles concernent, successivement, l'historiographie, l'archéologie et l'archéométrie, la chaîne opératoire, puis les questions de sociologie et d'économie. Ce livre se termine par des annexes comprenant une bibliographie très complète, la liste des échantillons analysés et les résultats des analyses, et la retranscription de quatre inventaires de manufacture après décès caractéristiques des différentes périodes étudiées.

5 Le deuxième tome, consacré à L'âge d'or $d u$ XVII siècle, se divise en trois parties. La première commence par une rapide évocation générale de la faïence en France jusqu'à la fondation du premier atelier nivernais en 1585 , avant de présenter la ville de Nevers et le contexte dans lequel la faïence s'est implantée. Elle se poursuit par l'étude des différentes familles de décors produits au XVII ${ }^{\mathrm{e}}$ siècle, qu'il s'agisse des styles, genres ou modes de présentation dont on évoque les caractéristiques, les origines, les témoignages archéologiques, la datation et l'évolution. La deuxième partie, intitulée Histoire et productions: des débuts placés sous l'influence de la Renaissance italienne, est consacrée à la première période du XVII ${ }^{\mathrm{e}}$ siècle, qui se termine avec l'ouverture du canal de Briare en 1642. On étudie d'abord l'histoire des faïenciers et des manufactures, en présentant, au fur et à mesure au sein même de ce récit et de manière chronologique, les faïences datées ou datables qui servent de repères fiables à partir desquels on pourra ensuite situer les autres pièces. On examine ensuite les formes produites au cours de cette période, en s'appuyant notamment sur le mobilier issu des fouilles archéologiques, pour terminer avec la présentation et l'étude de l'ensemble des productions, regroupées par familles de décors. La troisième et dernière partie, Développement des manufactures et nouvelles productions: la naissance d'une industrie, suit une démarche identique en ce qui concerne la seconde période, qui court jusqu'à la fin $\mathrm{du} \mathrm{XVII}^{\mathrm{e}}$ siècle: histoire et pièces repères, formes, puis décors. 
6 Les tomes 3 et 4 , consacrés respectivement $\mathrm{au} \mathrm{XVIII}^{\mathrm{e}}$ et au XIX ${ }^{\mathrm{e}}$ siècle, seront publiés ultérieurement. 